\title{
Object-based eye movements: The eyes prefer to stay within the same object
}

\author{
Jan Theeuwes and SebastiaAn Mathôt \\ Vrije Universiteit, Amsterdam, The Netherlands \\ AND \\ Alan Kingstone \\ University of British Columbia, Vancouver, British Columbia, Canada
}

\begin{abstract}
The present study addressed the question of whether we prefer to make eye movements within or between objects. More specifically, when fixating one end of an object, are we more likely to make the next saccade within that same object or to another object? Observers had to discriminate small letters placed on rectangles similar to those used by Egly, Driver, and Rafal (1994). Following an exogenous cue, observers made a saccade to one end of one of the rectangles. The small target letter, which could be discriminated only after it had been fixated, could appear either within the same or at a different object. Consistent with object-based attention, we show that observers prefer to make an eye movement to the other end of the fixated same object, rather than to the equidistant end of a different object. It is concluded that there is a preference to make eye shifts within the same object, rather than between objects.
\end{abstract}

When one is confronted with a visual scene, it is immediately parsed into groups, surfaces, and objects (e.g., Palmer, 1999). Subsequently, attention is assumed to act on these perceptual groups, guiding attention to coherent objects. Studies investigating object-based attention typically show superior performance in detecting attributes of the same object, as compared with detecting attributes of different objects, when it is ensured that the absolute spatial positions are equivalent (e.g., Duncan, 1984; Vecera, 1994; Watson \& Kramer, 1999).

Egly, Driver, and Rafal (1994) introduced a now classic paradigm to investigate object-based attention. Observers viewed displays consisting of two adjacent vertically or horizontally oriented rectangles (similar to the display shown in Figure 1). After a few seconds, an abrupt onset cue was presented at one end of one of the rectangles. This abrupt onset cue automatically summoned covert attention to the end of the rectangle while observers maintained fixation in the center of the display. The observers had to detect the onset of a target (a white square) appearing at the end of one of the rectangles. The target could appear at the cued location but could also occur at the other end of the cued rectangle (invalidly cued same object) or could appear at the same distance from the cue at the end of the other rectangle (invalidly cued different object). The typical finding is that detection of targets presented at validly cued locations is fast. More important, however, detection for invalidly cued same-objectcued targets is faster than detection of targets presented at the same distance in the other object (invalidly cued different object). The reaction time (RT) difference between same and different objects is the classic objectbased attention effect.

Since the publication of this classic study, this result has been replicated in various ways, using different variants of the original paradigm (e.g., Behrmann, Zemel, \& Mozer, 1998; Hecht \& Vecera, 2007; Lamy \& Egeth, 2002; Moore, Yantis, \& Vaughan, 1998; Mortier, Donk, \& Theeuwes, 2003; Vecera, 1994; Watson \& Kramer, 1999). The prevailing view to explain these findings is that once a part of an object is attended, attention automatically "spreads" throughout the boundaries of the object. A target is detected more quickly when it is presented within the boundaries of an attended object than when it is presented within another object.

Even though there has been a great deal of research addressing the conditions that foster covert object-based attention, much less is known about how the perceptual grouping of a scene into objects affects overt attention (i.e., eye movements). Does the eye prefer to stay within the same object, or is there a preference to switch between objects? This question is important because recent studies have revealed that the relationship between covert and overt attention may not be as straightforward as previously assumed (see Belopolsky \& Theeuwes, 2009; Hunt \& Kingstone, 2003; Juan, Shorter-Jacobi, \& Schall, 2004). For example, Hunt and Kingstone showed a dissociation between attentional allocation and eye movements. In

J. Theeuwes, j.theeuwes@psy.vu.nl 


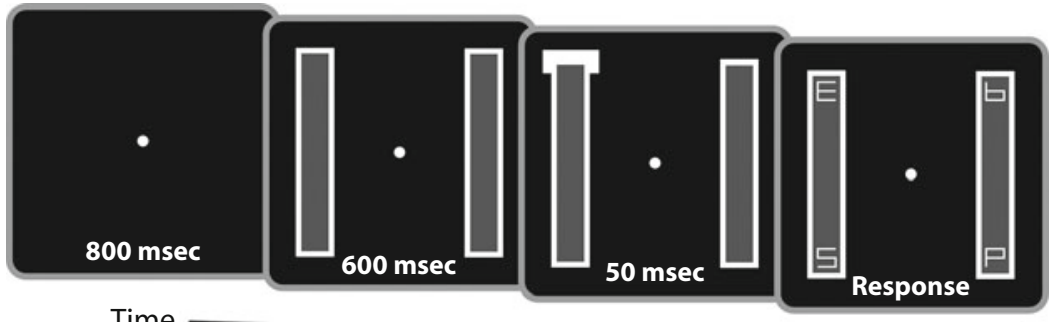

Figure 1. Schematic representation of an example trial in the saccade condition. Because the target letter ("E") and the cue are presented at the same location, this example depicts a validly cued trial. Note that the actual letters were very small, to ensure that the observers had to make a saccade to discern the identity of the target letter (not drawn to scale).

their dual-task study, saccade preparation did not result in an enhancement of target detection at the location of the prepared saccade, and maintaining attention did not result in facilitation of saccade initiation to the attended location (see also Klein, 1980). It is therefore not immediately clear whether the object-based attention effect would translate into a corresponding preference for eye movements to stay within an object.

The present study addressed the relationship between object-based attention and eye movements. To this end, we adapted the paradigm introduced by Egly et al. (1994), so that eye movements were required. Specifically, we asked the question of what people will do after they have made an initial saccade to a cued location. Are they more likely to make the second saccade within the fixated object, or are they are more likely to make a saccade between objects?

To date, only one study has addressed the issue of object-based saccades. McCarley, Kramer, and Peterson (2002) also used the classic Egly et al. (1994) paradigm and had observers make eye movements across the display. The observers had to respond to the orientation of a large T-shaped target among large L-shaped distractors. McCarley et al. forced the observers to make a saccade by using a gaze-contingent control of the display: Only after the observers encroached upon any one of the four potential target/distractor locations were all the target and distractor letters revealed. McCarley et al. showed that when the target object was presented within the same object on $82 \%$ of the trials, the observers directly moved their eyes to that object. When the target object was presented at a different object, the observers were slightly less likely (71\%) to saccade directly to the target. Even though this suggests that observers prefer to shift gaze within an object, rather than between objects, it is important to note that the McCarley et al. study applies only to the special case in which, after executing the first saccade, observers have full preview of the target and distractors. So, given that a target is present within the same object, there is a tendency to stay within the same object. Therefore, the tendency to move the eyes more often within the same object, rather than between objects, may be the result of differences in allocating covert attention to the potential target location before saccade execution. In the present study, we wanted to address the more general question of whether observers prefer to inspect locations within, rather than between, objects when no attentional preview is possible. In other words, if one fixates one part of an object, is there a tendency to choose as a next fixation a location within or between objects?

The present study investigated whether people are biased to make eye movements within, rather than between, objects. To ensure that no attentional preview was possible, we presented very small letters at the four ends of the two rectangles. Because these letters were too small to discern using peripheral vision, foveation was necessary to determine the identity of the letters. This ensured that if any object-based effects were to be found, they could not be attributed to attentional preview effects. In addition to this saccade condition, we also included an attentional condition to ensure that, with our stimuli, we would obtain the classic object-based attention effect.

\section{METHOD}

\section{Participants}

The observers were 13 paid volunteers, 19-45 years of age, recruited from the community of the University of British Columbia. All the observers had normal or corrected-to-normal visual acuity and were naive as to the purpose of the experiment. One observer was excluded from analysis because fixation was lost on too many trials $(69 \%)$

\section{Apparatus}

Eye movements were recorded using an Eyelink II (SR Research), a video-based eyetracker with a temporal resolution of $2 \mathrm{msec}$, a spatial resolution of $0.1^{\circ}$, and a maximum average gaze position error of $0.5^{\circ}$. Only the left eye was recorded. Eye movement data were recorded on a 1.8-GHz Pentium 4 laptop. The experiment was run on a $3-\mathrm{GHz}$ Pentium 4 PC, using a 17 -in. nonflat CRT display with a resolution of $1,024 \times 768$ pixels and a refresh rate of $60 \mathrm{~Hz}$. The experiment was conducted in a dimly lit room. The observers were requested to place their chin on a chinrest, the height of which was adjusted to their comfort.

\section{Stimuli}

Each trial started with the presentation of a gray fixation dot at the center of a black display (see Figure 1 for an example trial). Drift correction was performed using this fixation dot as a reference point. Two gray rectangles $\left(12^{\circ} \times 2^{\circ}\right)$, filled with a darker 
shade of gray, were presented at a distance of $5^{\circ}$ from the fixation dot $800 \mathrm{msec}$ after drift correction. With equal probability, the orientation of these rectangles was vertical, in which case they were presented to the left and right of the fixation dot, or horizontal, in which case they were presented above and below the fixation dot. After $600 \mathrm{msec}$, a cue (a $3^{\circ} \times 1^{\circ}$ gray rectangle) was flashed for $50 \mathrm{msec}$ in the corner of one of the rectangles, followed immediately by four letters, presented in each of the four corners. On validly cued trials ( $66 \%$ of the trials), the target letter ("E" or "H") appeared at the cued location. On invalidly cued, within-object trials ( $17 \%$ of the trials), the target letter was presented at the opposite end of the same rectangle. On invalidly cued, between-object trials $(17 \%)$, the target letter was presented at the same end of the other rectangle. The target letter was never presented at the opposite end of the other rectangle, relative to the cue. At the three other locations, distractor letters ("S," "b," and "P") were randomly presented, each letter being presented once. In the attention condition, the target letter $\left(1.8^{\circ} \times 1.8^{\circ}\right)$ was large, whereas the other letters were small $\left(0.4^{\circ} \times 0.4^{\circ}\right)$. In the saccade condition, all the letters were small $\left(0.4^{\circ} \times 0.4^{\circ}\right)$. The letters were constructed of an equal number of line segments, such that there were no luminance differences between the letters. The letters were presented until a manual response was given.

\section{Procedure and Design}

In the attention condition, the observers were instructed to maintain fixation at the central fixation dot. They were told that their eyes would be monitored. In the saccade condition, they were instructed to make saccades to find the target letter. The observers were required to make a speeded response regarding the identity of the target letter by pressing the "Z" key if the letter " $E$ " was presented and the "/" key if the letter " $\mathrm{H}$ " was presented. It was stressed that both accuracy and RT were important. Every 24 trials, visual feedback was presented, informing the observers of their average RT and the number of incorrect responses.

The experiment consisted of separate sessions consisting of attention and saccade conditions, each consisting of 48 practice trials and 192 experimental trials. The order of sessions was counterbalanced. The observers were told that the target letter would appear with a high probability at the cued location.

\section{RESULTS}

In the attention condition, trials on which gaze deviated more than $2^{\circ}$ from the fixation dot were discarded from analysis $(8.1 \%)$. For each observer, the RT standard deviation $(S D)$ was subsequently calculated per condition. Trials with an RT more than two times the $S D$ below or above the mean RT (per subject, per condition) were discarded (4.7\%). Trials on which the observers gave an incorrect manual response were few $(3.0 \%)$ and were not further analyzed. Fixations within a radius of $3^{\circ}$ from the center of a letter were considered to be on a letter. Small saccades within this area were considered to be the same fixation.

In the saccade condition, trials on which gaze deviated more than $2^{\circ}$ from the fixation dot, before the presentation of the cue, were discarded (10.5\%). Trials with an RT more than two times the $S D$ below or above the mean RT (per subject, per condition) (3.4\%) and trials on which an erroneous manual response was received $(2.5 \%)$ were excluded from the analysis.

In the attention condition, the mean manual RT for the validly cued condition ( $M=464 \mathrm{msec}, S E=7.6)$ was significantly shorter than that for either the invalidly cued same-object $[M=489 \mathrm{msec}, S E=10 ; t(11)=5.0$, $p<.001]$ or the invalidly cued different-object $[M=$ $501 \mathrm{msec}, S E=11.0 ; t(11)=6.2, p<.001]$ condition. More important, the difference between the invalidly cued same-object and invalidly cued different-object conditions was reliable [489 vs. $501 \mathrm{msec} ; t(11)=2.4, p<.05$ ], signifying the classic object-based attention effect. Note that this object-based attention effect of $12 \mathrm{msec}$ is very comparable to the classic object-based effect reported in Egly et al. (1994), as well as the object-based attention effects reported in other studies using similar displays (e.g., Hecht \& Vecera, 2007; Mortier et al., 2003; Richard, Lee, \& Vecera, 2008).

In the saccade condition, manual RTs for the validly cued condition $(M=802 \mathrm{msec}, S E=45)$ were significantly shorter than those for either the invalidly cued sameobject condition $[M=1,487 \mathrm{msec}, S E=53 ; t(11)=17.2$, $p<.001]$ or the invalidly cued different-object condition $[M=1,629 \mathrm{msec}, S E=56 ; t(11)=16.6, p<.001]$. Clearly also in the saccade condition, we found an objectbased effect on manual RT: Observers responded faster in the within-object condition $(M=1,487 \mathrm{msec})$ than in the between-object condition $(M=1,629 \mathrm{msec})[t(11)=3.2$, $p<.01]$. Figure 2 provides these results.

A subsequent analysis of saccades indicated that on $92.7 \%$ of the trials, saccades initially went to the cued location. After fixating the cued location, the observers were more likely to make a saccade within the same object $(M=55.8 \%, S E=3.3)$ than between objects $(M=$ $39.9 \%, S E=2.8)[t(11)=3.2, p<.01]$. The observers hardly made any diagonal saccades across the display to the location that never contained the target $(M=6.3 \%$; see Figure 3).

The initial saccade latency of the first saccade was relatively short $(M=266 \mathrm{msec}, S E=10.7)$. For the second saccade, there were no differences in saccade latencies for within-object $(M=382 \mathrm{msec}, S E=15.0)$ versus between-object $(M=376 \mathrm{msec}, S E=14.8)$ conditions $(t=0.5$, n.s. $)$.

To check whether the observers had any attentional preview of the target letter while fixating the invalidly cued location, we determined the extent to which a saccade within an object depended on the identity of the soon-to-be-fixated letter. If the observers could preview the letter within the object while fixating the invalidly cued location, one would expect that the probability of making a saccade within the same object would be higher when the letter in the object was a target, rather than a distractor, letter. Our results indicate that the probability of making a second saccade within the object did not depend on the identity of the soon-to-be-fixated letter. When the letter within the object was a target, on $54.7 \%$ of the trials, the eyes stayed within the object; when the letter within the object was a nontarget, on $48.7 \%$ of the trials, the observers stayed within the object. These numbers are not significantly different $[t(11)=1.36$, n.s.], providing evidence that attentional preview was not possible. 


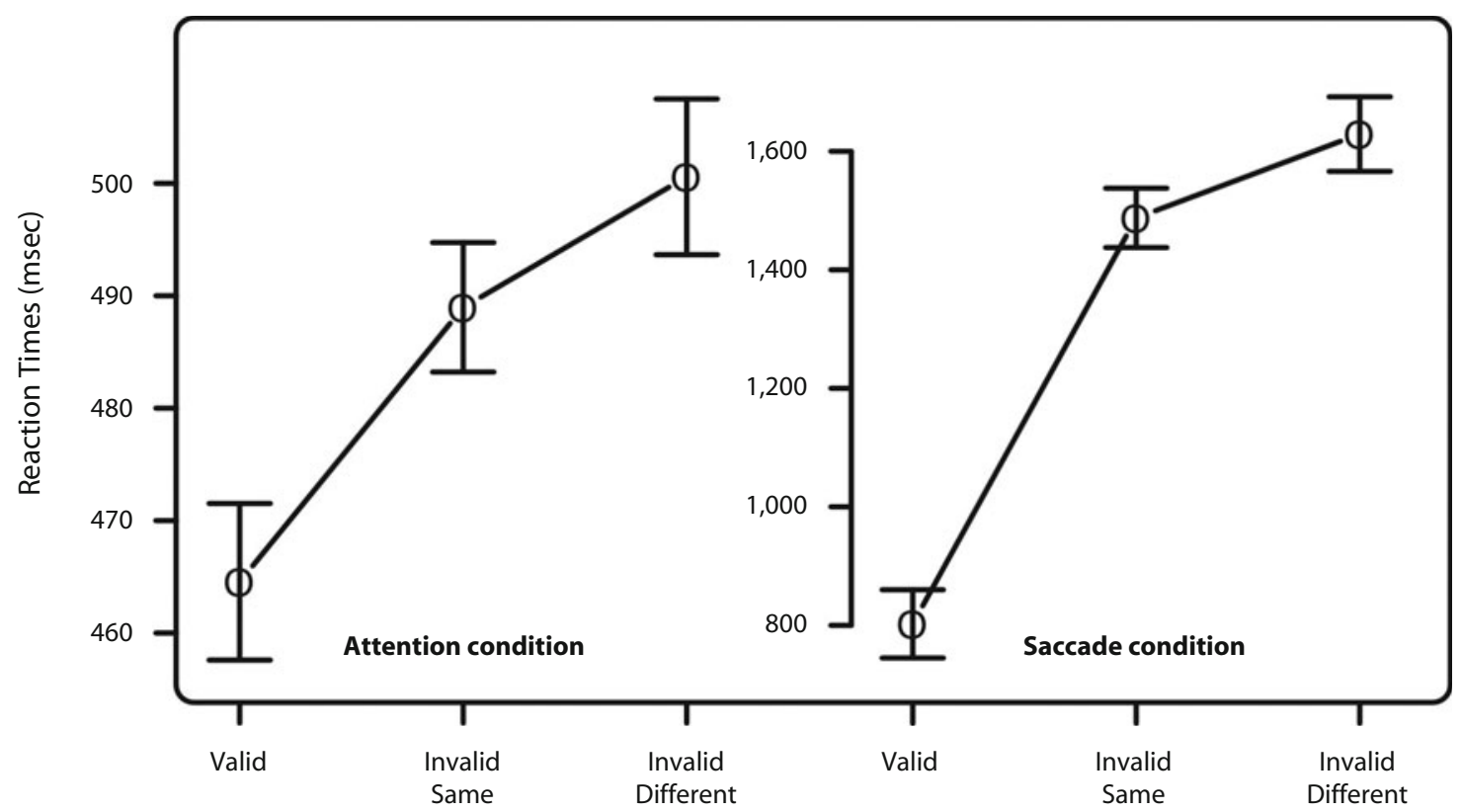

Figure 2. Mean manual reaction times for validly cued, invalidly cued same-object, and invalidly cued different-object conditions in the attention-only and eye movement conditions. The error bars indicate $95 \%$ within-subjects confidence intervals (Cousineau, 2005).

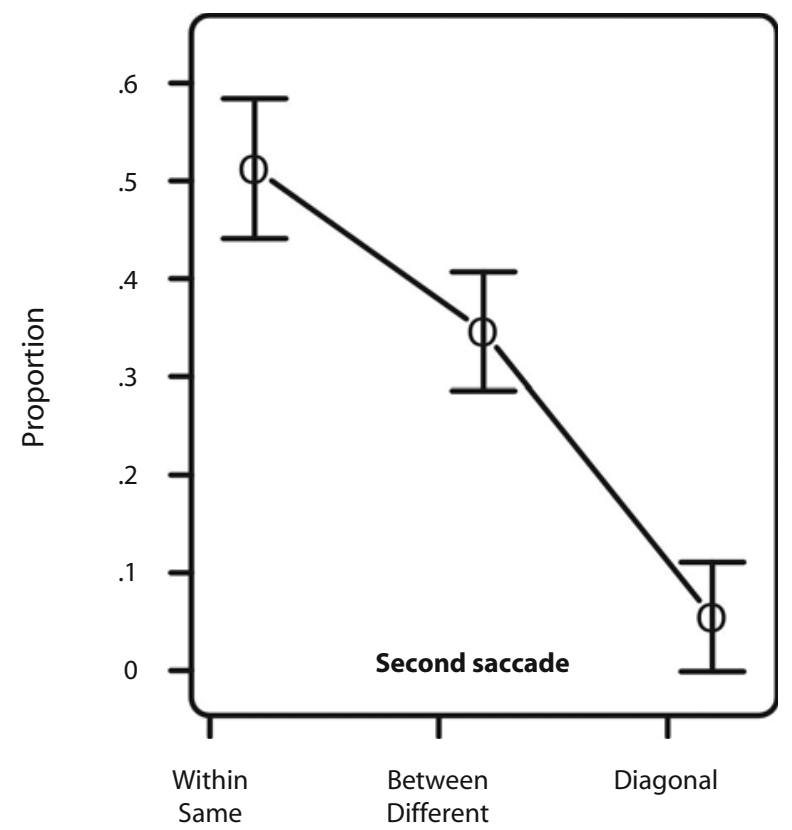

Figure 3. Mean proportions of second saccades made within the same object, between different objects, and diagonally.

\section{DISCUSSION}

The present study provides clear evidence for objectbased control of eye movements. In a display in which we obtained the classic object-based attention effect, we also found an object-based effect on the control of saccades. Even though the potential target locations were located equidistant from the cued target position, the observers were much more likely to make a saccade within the same object than between different objects. Our findings confirm and extend those of McCarley et al. (2002) in showing that even when there is no opportunity for extrafoveal processing of the target identity, observers still are more likely to saccade within rather than between objects. In other words, when no attentional preview is possible, independently of where the target object is located, there is 
a tendency to stay within the same object. If one fixates one part of an object, observers like to choose, as a next fixation, a location within that same object.

The RT pattern obtained in the attention condition is very similar to the pattern obtained in the condition in which the observers had to make a saccade (see Figure 2). Not surprisingly, however, the absolute manual RTs in the saccade condition were much larger than those in the attention-only condition because, in the saccade condition, the observers had to make one, possibly multiple eye movements before they could emit a response. Also, as was expected, in the saccade condition, the manual RTs reflected the eye movement pattern obtained: Because the observers were more likely to make a saccade within rather than between objects, the manual RTs in the within-object condition were much shorter than those in the between-object condition.

The present conclusion is consistent with the classic spreading-of-attention account of object-based attention (e.g., Richard et al., 2008; Vecera, 1994). Our results replicating the object-based attention effects suggest that once attention is captured by the abrupt onset to one side of the object, attention spreads within the object. Subsequently, one should ask the question of why observers are more likely to make a saccade within the object than between objects. There are at least two possible (potentially related) explanations for this effect. First, if one assumes that attention precedes an eye movement, as has been shown before (Deubel \& Schneider, 1996; Godijn \& Theeuwes, 2004), one can explain the within-object saccadic benefit as a result of the attentional benefit. Because attention spreads to the other side of the object, observers are more likely to execute a saccade to the location that is already attentionally activated than to the other object location that is not activated. Even though this is feasible, it seems less plausible, because the saccadic system needs a clear peak of focused attentional deployment to be able to launch a saccade (e.g., Godijn \& Theeuwes, 2002). The spreading of attention within the whole object does not seem to provide the distinct peak of localized activity that the saccadic system requires to launch a saccade. An alternative explanation of the present findings is related to the biased competition ideas of Desimone and Duncan (1995). Although biased competition typically refers to spatial attention, it is believed that there may also be competition between objects (e.g., Vecera, 2000). In this scenario, biased competition will lead to representation of one object, while the representation of other objects is inhibited (see also McCarley et al., 2002, for similar ideas). In the present experiment, competition was presumably biased toward selection of the cued (and therefore attended) object, resulting in inhibition of the unattended object. Because the representation of the unattended object is suppressed, observers are less likely to make a saccade to this object. According to this notion, the object-based saccade benefit is not necessarily due to attention's preceding the saccade at the within-object location but is due to object-based biased competition's suppressing the unattended object.

\section{AUTHOR NOTE}

We thank James R. Brockmole for his valuable comments. Correspondence concerning this article should be addressed to J. Theeuwes,
Department of Cognitive Psychology, Vrije Universiteit Amsterdam, van der Boechorststraat 1, 1081 BT Amsterdam, The Netherlands (e-mail: j.theeuwes@psy.vu.nl).

\section{REFERENCES}

Behrmann, M., Zemel, R. S., \& Mozer, M. C. (1998). Object-based attention and occlusion: Evidence from normal participants and a computational model. Journal of Experimental Psychology: Human Perception \& Performance, 24, 1011-1036.

Belopolsky, A.V., \& Theeuwes, J. (2009). When are attention and saccade preparation dissociated? Psychological Science, 20, 1340-1347.

Cousineau, D. (2005). Confidence intervals in within-subjects designs: A simpler solution to Loftus and Masson's method. Tutorial in Quantitative Methods for Psychology, 1, 42-45.

Desimone, R., \& Duncan, J. (1995). Neural mechanisms of selective visual attention. Annual Review of Neuroscience, 18, 193-222.

Deubel, H., \& Schneider, W. X. (1996). Saccade target selection and object recognition: Evidence for a common attentional mechanism. Vision Research, 36, 1827-1837.

DunCAN, J. (1984). Selective attention and the organization of visual information. Journal of Experimental Psychology: General, 113, 501517.

Egly, R., Driver, J., \& Rafal, R. D. (1994). Shifting visual attention between objects and locations: Evidence from normal and parietal lesion subjects. Journal of Experimental Psychology: General, 123, 161-177.

Godis, R., \& Theeuwes, J. (2002). Programming of exogenous and endogenous saccades: Evidence for a competitive integration model. Journal of Experimental Psychology: Human Perception \& Performance, 28, 1039-1054.

Godis, R., \& THEeUwES, J. (2004). The relationship between inhibition of return and saccade trajectory deviations. Journal of Experimental Psychology: Human Perception \& Performance, 30, 538-554.

Hecht, L. N., \& Vecera, S. P. (2007). Attentional selection of complex objects: Joint effects of surface uniformity and part structure. Psychonomic Bulletin \& Review, 14, 1205-1211.

Hunt, A. R., \& Kingstone, A. (2003). Covert and overt voluntary attention: Linked or independent? Cognitive Brain Research, 18, 102-105.

Juan, C. H., Shorter-Jacobi, S. M., \& Schall, J. D. (2004). Dissociation of spatial attention and saccade preparation. Proceedings of the National Academy of Sciences, 101, 15541-15544.

Klein, R. M. (1980). Does oculomotor readiness mediate cognitive control of visual attention? In R. S. Nickerson (Ed.), Attention and performance VIII (pp. 259-276). Hillsdale, NJ: Erlbaum.

Lamy, D., \& Egeth, H. (2002). Object-based selection: The role of attentional shifts. Perception \& Psychophysics, 64, 52-66.

McCarley, J. S., Kramer, A. F., \& Peterson, M. S. (2002). Overt and covert object-based attention. Psychonomic Bulletin \& Review, 9, 751758.

Moore, C. M., Yantis, S., \& Vaughan, B. (1998). Object-based visual selection: Evidence from perceptual completion. Psychological Science, 9, 104-110.

Mortier, K., Donk, M., \& Theeuwes, J. (2003). Attentional capture within and between objects. Acta Psychologica, 113, 133-145.

Palmer, S. E. (1999). Vision science: Photons to phenomenology. Cambridge, MA: MIT Press.

Richard, A. M., Lee, H., \& Vecera, S. P. (2008). Attentional spreading in object-based attention. Journal of Experimental Psychology: Human Perception \& Performance, 34, 842-853.

VECERA, S. P. (1994). Grouped locations and object-based attention: Comment on Egly, Driver, and Rafal (1994). Journal of Experimental Psychology: General, 123, 316-320.

VECERA, S. P. (2000). Toward a biased competition account of objectbased segregation and attention. Brain \& Mind, 1, 353-384.

Watson, S. E., \& Kramer, A. F. (1999). Object-based visual selective attention and perceptual organization. Perception \& Psychophysics, 61, 31-49.
(Manuscript received September 9, 2009; revision accepted for publication October 26, 2009.) 